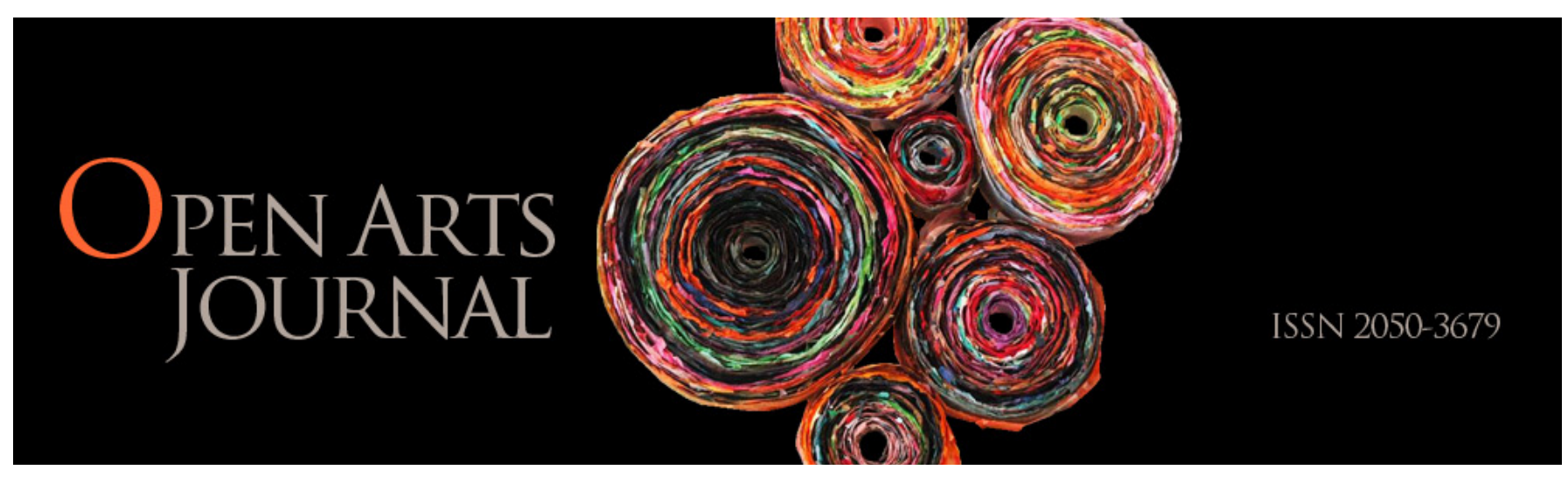

\title{
GOOGLE PAINTINGS
}

\section{John Timberlake}

The Google Paintings are sketches in oil paints on prepared paper, mounted under glass. Over a period of two years, I conducted a 'Grand Tour' via Google Earth, visiting locations across the globe of topical and newsworthy interest, and making paintings of what I saw. Given the absence of skies in Google Earth, I composed cloudscapes appropriate to the mood and occasion. These paintings were made between 2007 and 2009, and were first exhibited in the group exhibition Beyond the Picturesque, curated by Frank Maes and Steven Jacobs, at the Stedelijk Museum voor Actuele Kunst, Gent, Belgium (April - August 2009).

\section{John Timberlake}

John Timberlake (b. 1967, Lancashire) is a London based artist. His recent exhibitions include:'Ron Haselden/ John Timberlake' (Galerie des Petits Carreaux, Paris 2012); 'Dark Sky' (Te Pataka Toi Adam Gallery,Victoria University, Wellington, NZ, 20I2); 'The Ends of Art' (Beton 7, Athens 20I3); 'Art in a Media Age', Imperial War Museum of the North, (Manchester 20I3). His work is held in a number of public and private collections in the UK, Europe and the US. Timberlake teaches Fine Art at Middlesex University. 


\section{GOOGLE PAINTINGS}

\section{John Timberlake}

The Google Paintings are sketches in oil paints on prepared paper, mounted under glass. Over a period of two years, I conducted a 'Grand Tour' via Google Earth, visiting locations across the globe of topical and newsworthy interest, and making paintings of what I saw. Given the absence of skies in Google Earth, I composed cloudscapes appropriate to the mood and occasion.
These paintings were made between 2007 and 2009, and were first exhibited in the group exhibition Beyond the Picturesque, curated by Frank Maes and Steven Jacobs, at the Stedelijk Museum voor Actuele Kunst, Gent, Belgium (April - August 2009).

All images courtesy Galerie des Petits Carreaux, Paris.

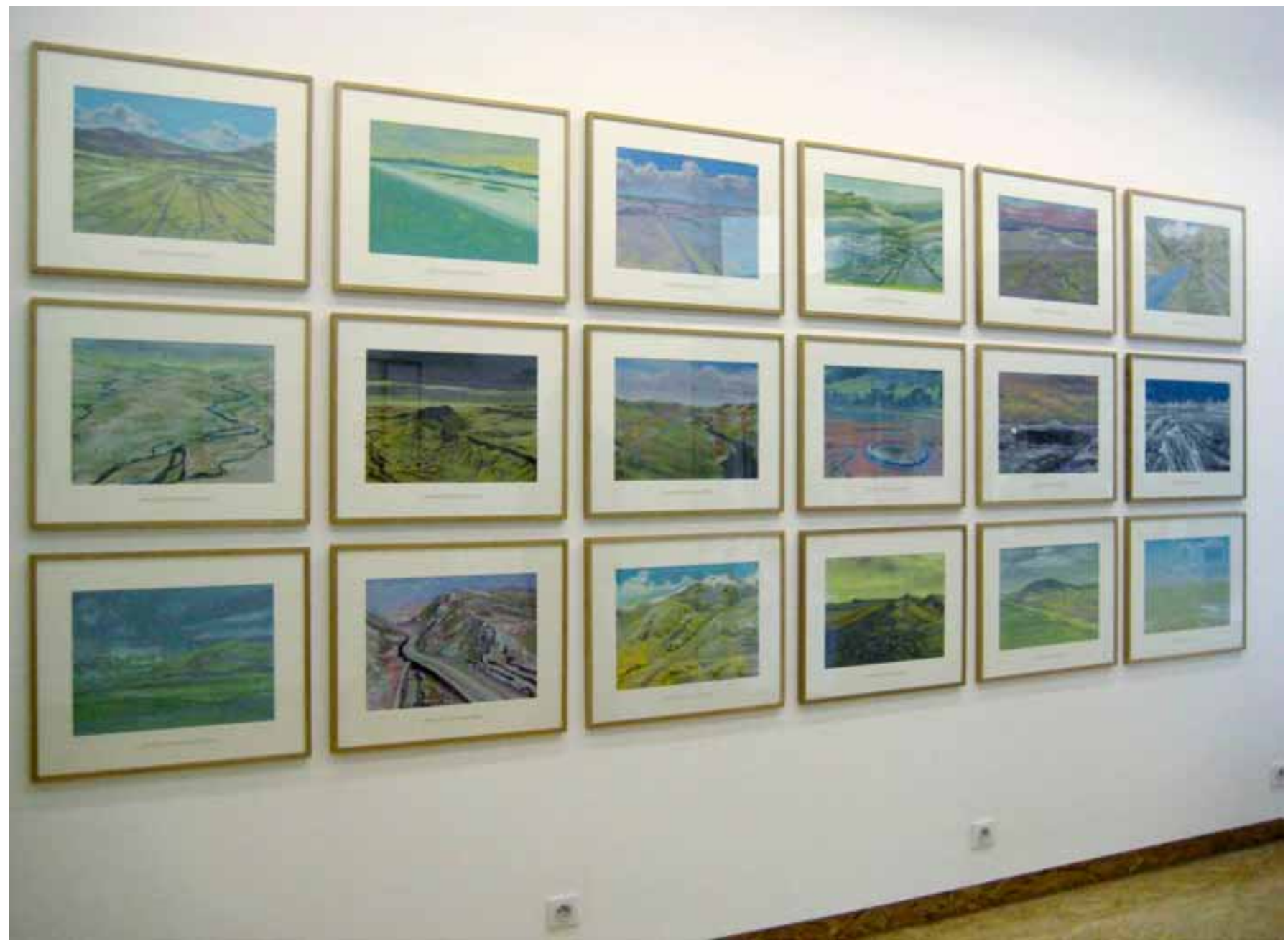



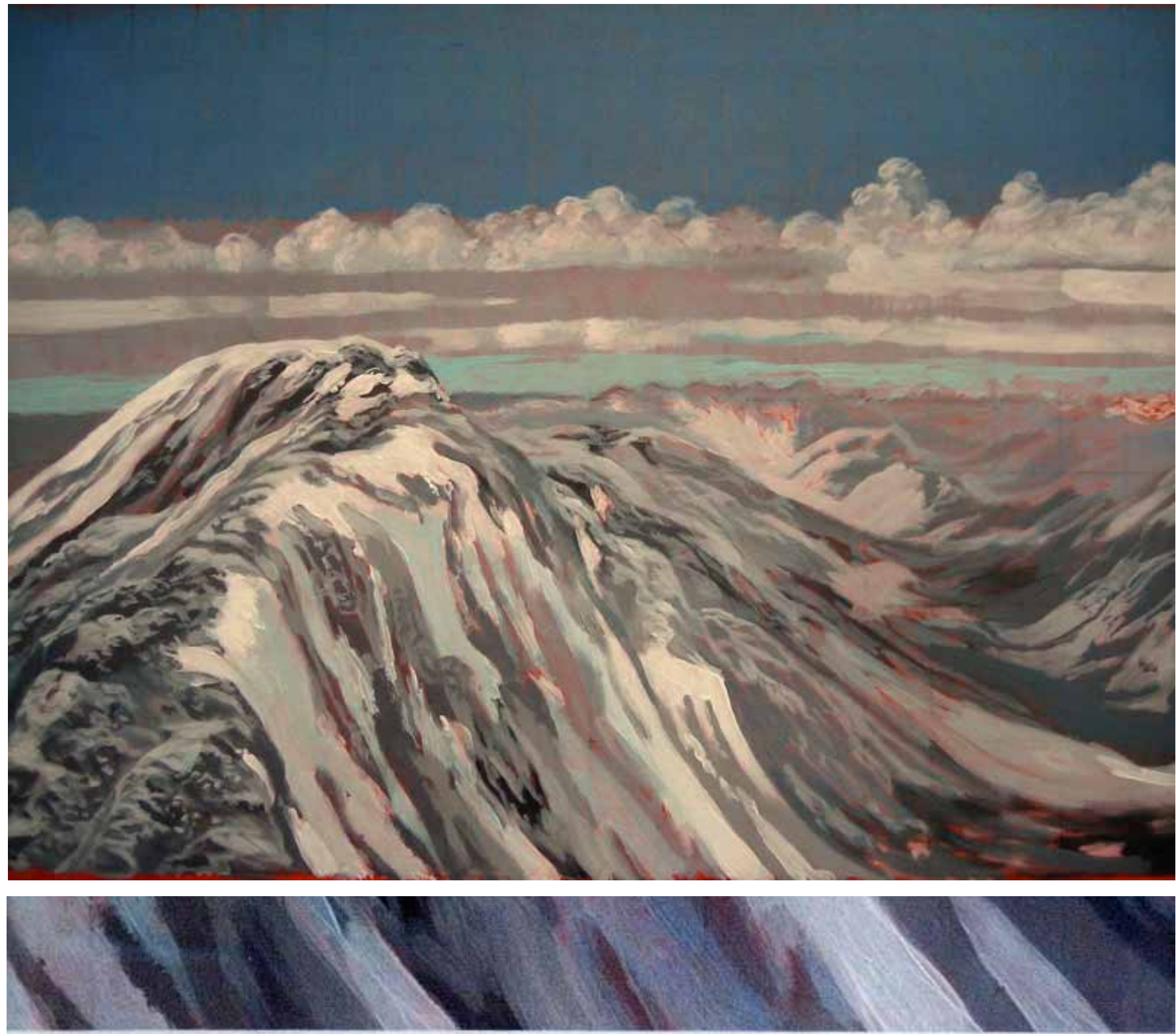

Pointer $42^{\circ} 45^{\prime} 28.72^{\prime \prime} \mathrm{N} \quad 0^{\circ} 32^{\prime} 58.25^{\prime \prime} \mathrm{W}$ elev $2133 \mathrm{~m}$ Eye alt $2.69 \mathrm{~km}$ 

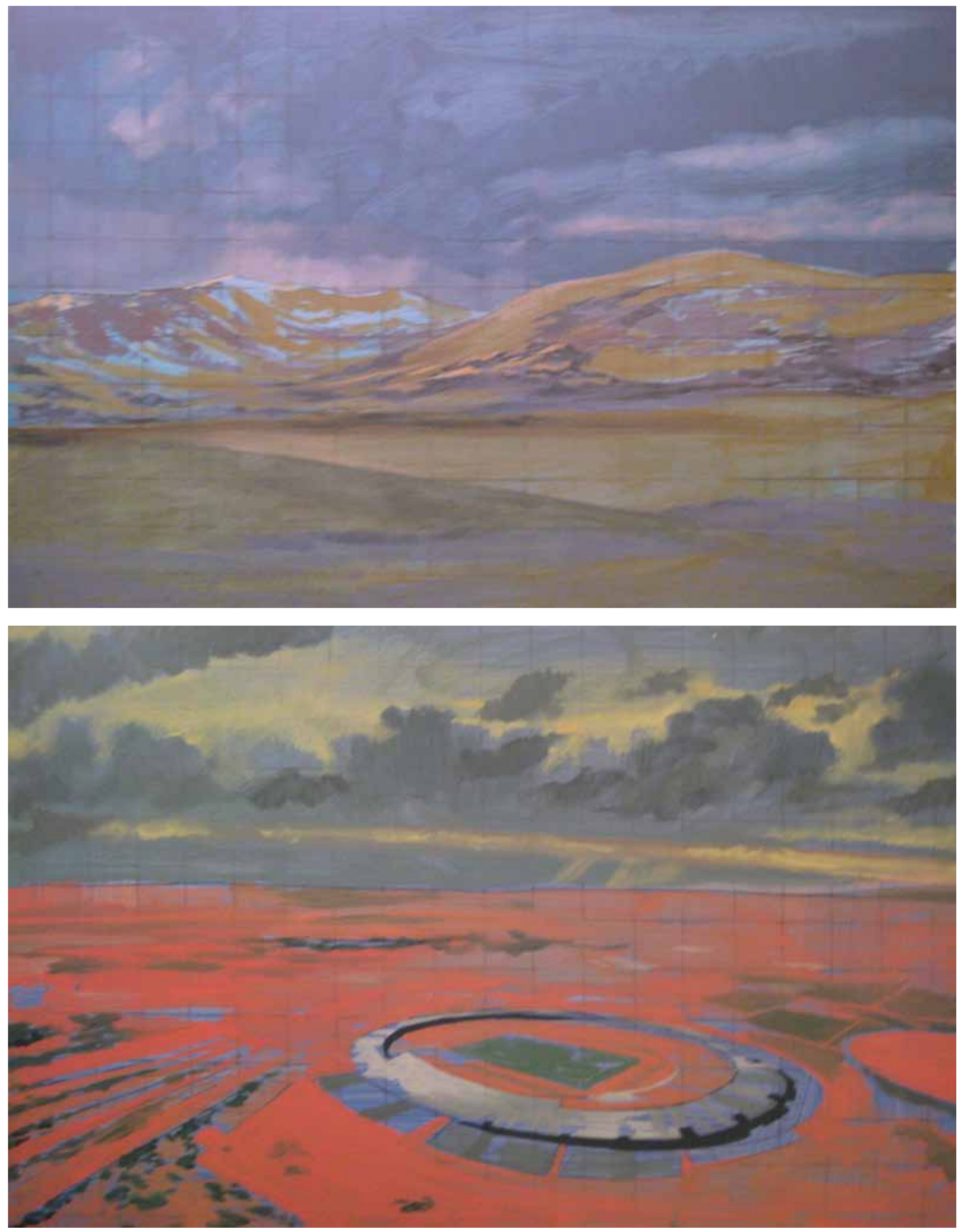


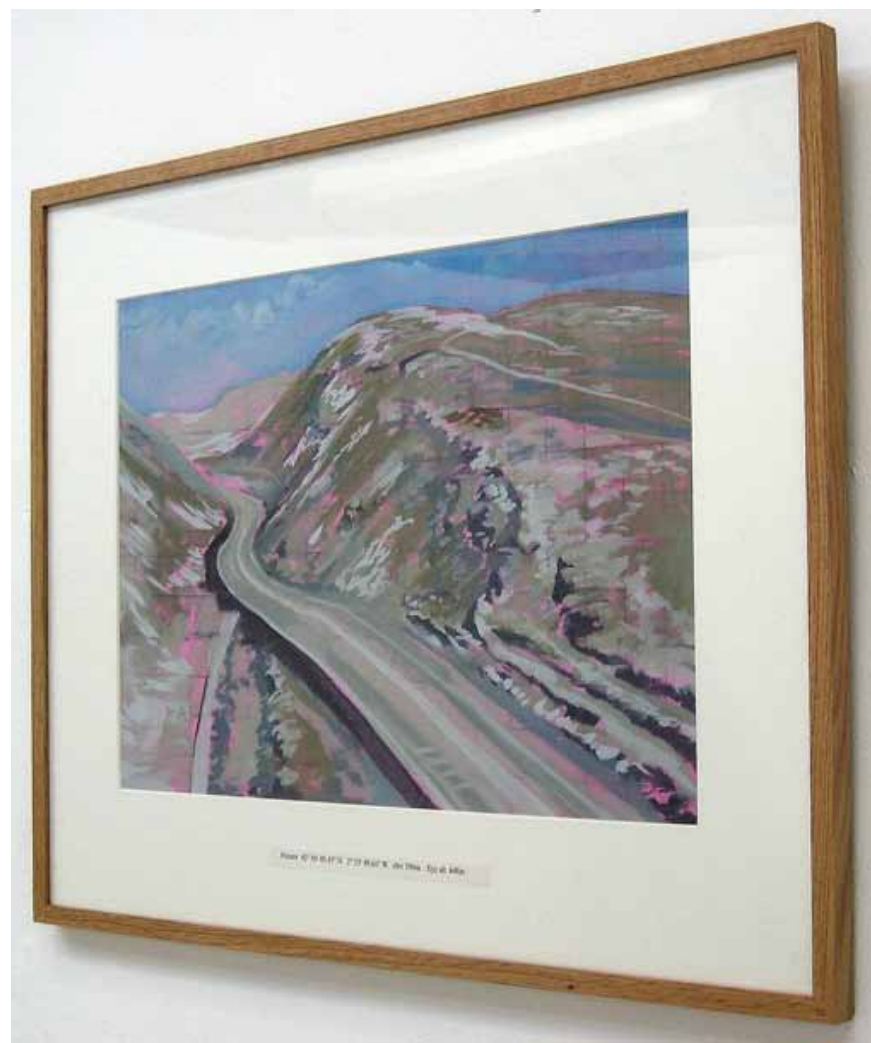

